Nuclear Science and Technology Division

\title{
Partitioning of Tank Waste Sludge in a 5-cm Centrifugal Contactor Under Caustic-Side Solvent Extraction Conditions
}

J. F. Birdwell, Jr.

K. K. Anderson

Prepared for the

DOE Office of Environmental Management and the

Tanks Focus Area Salt Processing Project DOE Office of Science and Technology

Prepared by

OAK RIDGE NATIONAL LABORATORY

Oak Ridge, Tennessee 37831-6285

managed by

UT-BATTELLE, LLC

for the

U.S. DEPARTMENT OF ENERGY

under contract DE-AC05-00OR22725 


\section{CONTENTS}

ABSTRACT............................... V

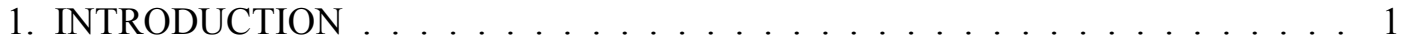

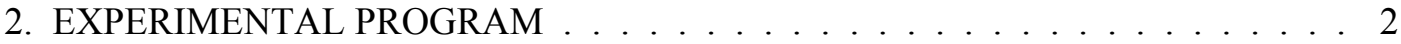

2.1 Equipment . . . . . . . . . . . . . . . . . . . . . 5

2.2 Test Procedures . . . . . . . . . . . . . . . . . . . . . . 5

2.2.1 Sludge Shakeout Test Procedure . . . . . . . . . . . . . 5

2.2.2 Contactor Solids Partitioning Procedure. . . . . . . . . . . . . . . 7

3. RESULTS .............................. . . . 8

3.1 Solids-Phase Partitioning . . . . . . . . . . . . . . . . . . . 8

3.2 Contactor Solids Partitioning . . . . . . . . . . . . . . . . 8

4. DISCUSSION AND CONCLUSIONS . . . . . . . . . . . . . . . . 11

5. REFERENCES ........................... . . 12 


\begin{abstract}
A test program has been performed to evaluate the effect of solids on the hydraulic performance of a 5-cm centrifugal contactor under conditions present in the extraction section of the Caustic-Side Solvent Extraction (CSSX) process. In addition to determining if the ability to separate the aqueous and organic phases is affected by the presence of solids in a feed solution, the extent to which solids are accumulated in the contactor was also assessed.

The reported task was motivated by the need to determine if removal of cesium from Savannah River Site tank waste can be performed using a contactor-based CSSX process without first removing sludge that is suspended in the feed solution. The ability to pass solids through the CSSX process could facilitate placement of CSSX upstream of a process in which alpha-decaying actinides and strontium are removed from the waste stream by precipitation with monosodium titanate (MST). This relative placement of the CSSX and MST processes is desirable because removal of cesium would greatly reduce the activity level of the feed stream to the MST process, thereby reducing the level of shielding needed and mitigating remote maintenance design features of MST equipment. Both results would significantly reduce the cost of the Salt Processing Project.

Test results indicate conclusively that a large fraction of suspended sludge that enters the centrifugal contactor remains inside. It is expected that extended operation would result in continued accumulation of solids and that hydraulic performance would be adversely affected. Results also indicate that a fraction of the solids partitions to the phase boundary and could affect phase separation as contactor operations progress.
\end{abstract}




\section{INTRODUCTION}

An important consideration in the design and operation of any centrifugal contactor-based solvent extraction process is the presence or formation of solids in any of the feed solutions. In contactor-based actinide separation processes (fuel reprocessing and nuclear material manufacture), a general guideline for system design and operation has been that at least $99 \%$ of solids greater than $1 \mathrm{Fm}$ in size should be removed from all feed solutions. Experience with centrifugal contactors has shown that the contactor at which a solids-containing feed solution enters the extraction cascade will act as a clarifier, effectively removing the majority of the solids present. This situation is acceptable only if solids occur very infrequently and if the total mass of solids entering the contactor system is small. Transfer of any significant quantity of solids to a contactor cascade or frequent transfer of smaller quantities typically results in partial or complete blockage of a solution flow path within the contactor. If the blockage is severe enough, the pressure drop in the contactor will become sufficient to cause accumulation of liquid in the contactor (the flooding condition). More commonly, a partial blockage is formed in the path of heavy-phase flow through the contactor, which results in a shift in the phase boundary inside the rotor to a position under the light-phase weir. In this case, the light-phase contactor effluent becomes contaminated with the more dense process solution.

Evaluation of solids behavior in centrifugal contactors under conditions simulating those in the extraction section of the Caustic-Side Solvent Extraction (CSSX) process served two purposes. First, examination of solids partitioning as a function of size provides an indication of the level of solids removal that should be included in the design of systems that supply feed solutions to CSSX. Second, should solids present in the CSSX supernatant feed partition to the aqueous phase and exit the system in the raffinate, precipitation and filtering of actinides and strontium from waste supernatant could be performed downstream of CSSX without the need for a duplicate filtration step upstream of the CSSX cascade. Removal of cesium from the waste stream prior to alpha-actinide/strontium removal would greatly reduce the amount of radioactivity in the feed stream to this process, thereby reducing the engineering complexity and cost of the process system.

Conceptually, accumulation of solids in centrifugal contactors to some finite mass or volume would be acceptable if the limit value does not result in loss of phase separation performance and if solids in excess of the accumulation value partition to the aqueous raffinate. However, a significant period of transitional operation would occur while solids accumulate to the limit value in all stages downstream from the feed stage. System performance during this period would be 
unpredictable. The ability to maintain acceptable contactor operation under modified flow conditions or during minor process upsets would also be highly uncertain.

For evaluation purposes, unacceptable outcomes of the test effort are (1) retention of solids inside the contactor such that hydraulic performance is affected adversely, (2) partitioning of solids to the interface and subsequent formation of a stable interfacial layer consisting of aqueous and organic phases and suspended sludge, and (3) partitioning of solids to the organic phase. The last outcome would necessitate the inclusion of a filtration step between CSSX and the solventwashing process to prevent accumulation of solids in the recycled solvent.

\section{EXPERIMENTAL PROGRAM}

Testing was performed in two phases. In the first, sludge partitioning between simulated Savannah River Site (SRS) supernatant and CSSX solvent was evaluated in shakeout tests. Tests were performed at organic-to-aqueous volume ratios that correspond to the flow ratios specified for the extraction section of the CSSX process. The purposes of this effort were to observe sludge partitioning under gravity settling conditions in order to predict partitioning behavior in a contactor and to determine if the presence of solids resulted in stabilization of the organic/aqueous dispersion. In the second phase of testing, the partitioning of sludge between aqueous and organic effluents from a centrifugal contactor and the accumulation of sludge inside the contactor were examined.

The composition of the sludge simulant used in testing is detailed in Table 1. Sludge used in all tests described in this report consisted of a 50-50 mixture (by weight) of the two formulations presented in the table. All solids tests were performed at a sludge concentration in the supernatant of $600 \mathrm{ppm}$ (milligrams per liter). The 600-ppm value and a higher 1200-ppm concentration were provided by SRS as bounding a representative range of sludge content in the supernatant. ${ }^{1}$ The higher value was to be used in follow-on tests that were to be performed if solids did not accumulate during testing at the lower concentration.

Supernatant simulant, prepared according to a procedure developed at SRS, ${ }^{2}$ had the composition shown in Table 2.

Solvent used in both phases of testing had been used previously in dispersion number determinations and in contactor hydraulic and mass transfer tests. Prior to its use in the sludge partitioning test and in the first and third contactor solids tests, the solvent was scrubbed with $0.05 \mathrm{MHNO}_{3}$, stripped with $0.001 M \mathrm{HNO}_{3}$, and washed with $0.01 \mathrm{MNaOH}$. 
Table 1. Compositions of SRS sludge simulants

\begin{tabular}{|c|c|c|}
\hline & $\mathrm{HM}^{a}$ sludge & PUREX ${ }^{b}$ sludge \\
\hline \multicolumn{3}{|l|}{ Solids (wt \%) } \\
\hline Insoluble solids & 12.9 & 12.5 \\
\hline Soluble solids & 2.87 & 3.28 \\
\hline Total solids & 15.4 & 15.4 \\
\hline \multicolumn{3}{|c|}{ Component (wt \% dry basis) } \\
\hline $\mathrm{Al}(\mathrm{OH})_{3}$ & 25.8 & 10.9 \\
\hline $\mathrm{BaSO}_{4}$ & 0.23 & 0.45 \\
\hline $\mathrm{Ca}_{3}\left(\mathrm{PO}_{4}\right)_{2}$ & 0.10 & 0.23 \\
\hline $\mathrm{CaCO}_{3}$ & 1.52 & 4.57 \\
\hline $\mathrm{CaSO}_{4}$ & 0 & 0.42 \\
\hline $\mathrm{Cr}_{2} \mathrm{O}_{3}$ & 0.23 & 0.36 \\
\hline $\mathrm{CsNO}_{3}$ & 0.026 & 0.0029 \\
\hline $\mathrm{CuO}$ & 0.056 & 0.16 \\
\hline $\mathrm{Fe}(\mathrm{OH})_{3}$ & 26.7 & 45.5 \\
\hline $\mathrm{HgO}$ & 0 & 0 \\
\hline $\mathrm{KNO}_{3}$ & 0.019 & 0.017 \\
\hline $\mathrm{KOH}$ & 0.18 & 0.35 \\
\hline $\mathrm{MgO}$ & 0.35 & 0.22 \\
\hline $\mathrm{MnO}_{2}$ & 6.86 & 6.50 \\
\hline $\mathrm{Mn}_{3} \mathrm{O}_{4}$ & 0.77 & 0.73 \\
\hline $\mathrm{Na}_{2} \mathrm{CO}_{3}$ & 0.11 & 0.13 \\
\hline $\mathrm{Na}_{2} \mathrm{SO}_{4}$ & 0.49 & 0.15 \\
\hline $\mathrm{Na}_{3} \mathrm{PO}_{4}$ & 0.042 & 0.011 \\
\hline $\mathrm{NaCl}$ & 0.49 & 1.37 \\
\hline $\mathrm{NaF}$ & 0.27 & 0.24 \\
\hline $\mathrm{NaI}$ & 0 & 0.024 \\
\hline $\mathrm{NaNO}_{2}$ & 11.9 & 11.9 \\
\hline $\mathrm{NaNO}_{3}$ & 1.28 & 1.28 \\
\hline $\mathrm{NaOH}$ & 1.41 & 3.11 \\
\hline $\mathrm{Nd}_{2} \mathrm{O}_{3}$ & 2.41 & 0.22 \\
\hline $\mathrm{Ni}(\mathrm{OH})_{2}$ & 1.35 & 4.00 \\
\hline $\mathrm{PbSO}_{4}$ & 0.23 & 0.45 \\
\hline $\mathrm{SiO}_{2}$ & 5.20 & 1.48 \\
\hline $\mathrm{SrCO}_{3}$ & 0.42 & 0.034 \\
\hline Zeolite & 9.63 & 1.47 \\
\hline $\mathrm{ZnO}$ & 0.044 & 0.30 \\
\hline $\mathrm{ZrO}_{2}$ & 1.90 & 3.40 \\
\hline
\end{tabular}

${ }^{a}$ An acronym for "H-Modified," a modified PUREX process used in the H Canyon at SRS.

${ }^{b}$ Process used to separate uranium and plutonium from each other and from fission products by means of solvent extraction. 
Table 2. Composition of supernatant simulant

\begin{tabular}{|c|c|c|}
\hline Compound & Molecular Weight & $\operatorname{Mass}(\mathrm{g} / \mathrm{L})$ \\
\hline $\mathrm{KNO}_{3}$ & 101.10 & 1.517 \\
\hline $\mathrm{CsCl}$ & 168.37 & 0.024 \\
\hline $\mathrm{NaOH}$ & 40.00 & 127.48 \\
\hline $\mathrm{NaNO}_{3}$ & 84.99 & 99.85 \\
\hline $\mathrm{NaNO}_{2}$ & 69.00 & 34.5 \\
\hline $\mathrm{Al}\left(\mathrm{NO}_{3}\right)_{3}-9 \mathrm{H}_{2} \mathrm{O}$ & 375.14 & 105.04 \\
\hline $\mathrm{Na}_{2} \mathrm{CO}_{3}-\mathrm{H}_{2} \mathrm{O}$ & 124.01 & 18.6 \\
\hline $\mathrm{Na}_{2} \mathrm{SO}_{4}$ & 142.04 & 19.89 \\
\hline $\mathrm{NaCl}$ & 58.44 & 1.403 \\
\hline $\mathrm{NaF}$ & 41.99 & 1.176 \\
\hline $\mathrm{Na}_{2}\left(\mathrm{HPO}_{4}\right)-7 \mathrm{H}_{2} \mathrm{O}$ & 268.09 & 1.877 \\
\hline $\mathrm{Na}_{2} \mathrm{C}_{2} \mathrm{O}_{4}$ & 134.00 & 1.072 \\
\hline $\mathrm{Na}_{2} \mathrm{SiO}_{3}-9 \mathrm{H}_{2} \mathrm{O}$ & 284.20 & 8.526 \\
\hline $\mathrm{Na}_{2} \mathrm{MoO}_{4}-2 \mathrm{H}_{2} \mathrm{O}$ & 241.95 & 0.019 \\
\hline $\mathrm{NH}_{4} \mathrm{NO}_{3}$ & 80.04 & 0.08 \\
\hline $\mathrm{H}_{2} \mathrm{O}$ & 18.02 & 836.9 \\
\hline $\mathrm{CuSO}_{4}-5 \mathrm{H}_{2} \mathrm{O}$ & 249.68 & 0.00566 \\
\hline $\mathrm{Na}_{2} \mathrm{CrO}_{4}$ & 161.97 & 0.2336 \\
\hline $\mathrm{Zn}\left(\mathrm{NO}_{3}\right)_{2}-6 \mathrm{H}_{2} \mathrm{O}$ & 297.47 & 0.0364 \\
\hline $\mathrm{Pb}\left(\mathrm{NO}_{3}\right)_{2}$ & 331.20 & 0.00336 \\
\hline $\mathrm{Fe}\left(\mathrm{NO}_{3}\right)_{3}-9 \mathrm{H}_{2} \mathrm{O}$ & 404.00 & 0.01042 \\
\hline $\mathrm{SnCl}_{2}-2 \mathrm{H}_{2} \mathrm{O}$ & 225.63 & 0.00456 \\
\hline $\mathrm{Hg}\left(\mathrm{NO}_{3}\right)_{2}-\mathrm{H}_{2} \mathrm{O}$ & 342.61 & 0.0000854 \\
\hline $\mathrm{Rh}\left(\mathrm{NO}_{3}\right)_{3}-2 \mathrm{H}_{2} \mathrm{O}$ & 324.95 & 0.000663 \\
\hline $\mathrm{Pd}\left(\mathrm{NO}_{3}\right)_{2}$ & 230.43 & 0.000888 \\
\hline $\mathrm{AgNO}_{3}$ & 169.87 & 0.0000157 \\
\hline $\mathrm{RuCl}_{3}$ & 207.43 & 0.00168 \\
\hline $\mathrm{TBP}^{a}$ & 266.32 & 0.0005 \\
\hline $\mathrm{DBP}^{b}$ & 210.21 & 0.025 \\
\hline $\mathrm{MBP}^{c}$ & 154.10 & 0.025 \\
\hline n-Butanol & 74.12 & 0.002 \\
\hline $\mathrm{NaCHO}_{2}$ & 68.01 & 1.5 \\
\hline Trimethylamine & 59.11 & 0.01 \\
\hline
\end{tabular}

${ }^{a}$ Tributyl phosphate.

${ }^{b}$ Dibutyl pyosphate.

${ }^{c}$ Monobutyl phosphate. 


\subsection{Equipment}

Equipment used in contactor testing was arranged as shown in Fig. 1. The contactor used was procured from CINC, Inc. (Carson City, NV), as a standard-design item (model V-2). Prior to its use, the opening at the bottom of the contactor rotor was enlarged to convert the unit to the partially pumping operating mode. In addition, a rotor housing bottom with straight radial vanes was used in place of the curved vane assembly supplied by the vendor. This contactor configuration is consistent with one that was used in the most recent contactor mass transfer test performed prior to the solids partitioning test. Mass transfer efficiencies obtained using the contactor "as received" were unacceptable. The modifications applied in the solids partitioning test have been found to increase cesium transfer efficiencies to acceptable levels. ${ }^{3}$

Solutions were supplied to the contactor by piston-type metering pumps (Fluid Metering Inc., Model QV-2). The pump heads were equipped with 300 series stainless steel sleeves and pistons.

The vessels used to supply and receive solutions (15-L-capacity high-density polyethylene tanks) were procured from VWR Scientific Products (Oak Ridge, TN, catalog no. 60464-043). All tubing used during testing was PFA Teflon ${ }^{\circledR}$; all tubing fittings had been fabricated from 304L stainless steel.

\subsection{Test Procedures}

\subsubsection{Sludge Shakeout Test Procedure}

Using a 100-mL graduated cylinder, sludge was added to $60 \mathrm{~mL}$ of simulated supernatant to a concentration of $600 \mathrm{ppm}$ (milligrams per liter). To simulate the solutions present in the extraction section of CSSX, $3.9 \mathrm{~mL}$ of scrub solution $\left(0.05 M \mathrm{HNO}_{3}\right)$ and $19.7 \mathrm{~mL}$ of CSSX solvent were added to the graduate. A ground glass stopper was placed in the graduate, which was then agitated manually for $20 \mathrm{~s}$. After suspending agitation for $10 \mathrm{~s}$, the graduate was shaken for another $20 \mathrm{~s}$. The dispersion formed was allowed to separate by gravity, and the partitioning of solids among the bulk phases and interface was observed. The intent was to collect, wash, dry, and weigh the solids if partitioning was limited to the bulk organic phase and/or the bulk aqueous phase. As will be described subsequently in this report, a large fraction of solids present in the system partitioned to the phase boundary, making precise collection of solids from discrete locations extremely difficult. Nonetheless, solids were collected from the phases in order to quantify partitioning to some extent. 


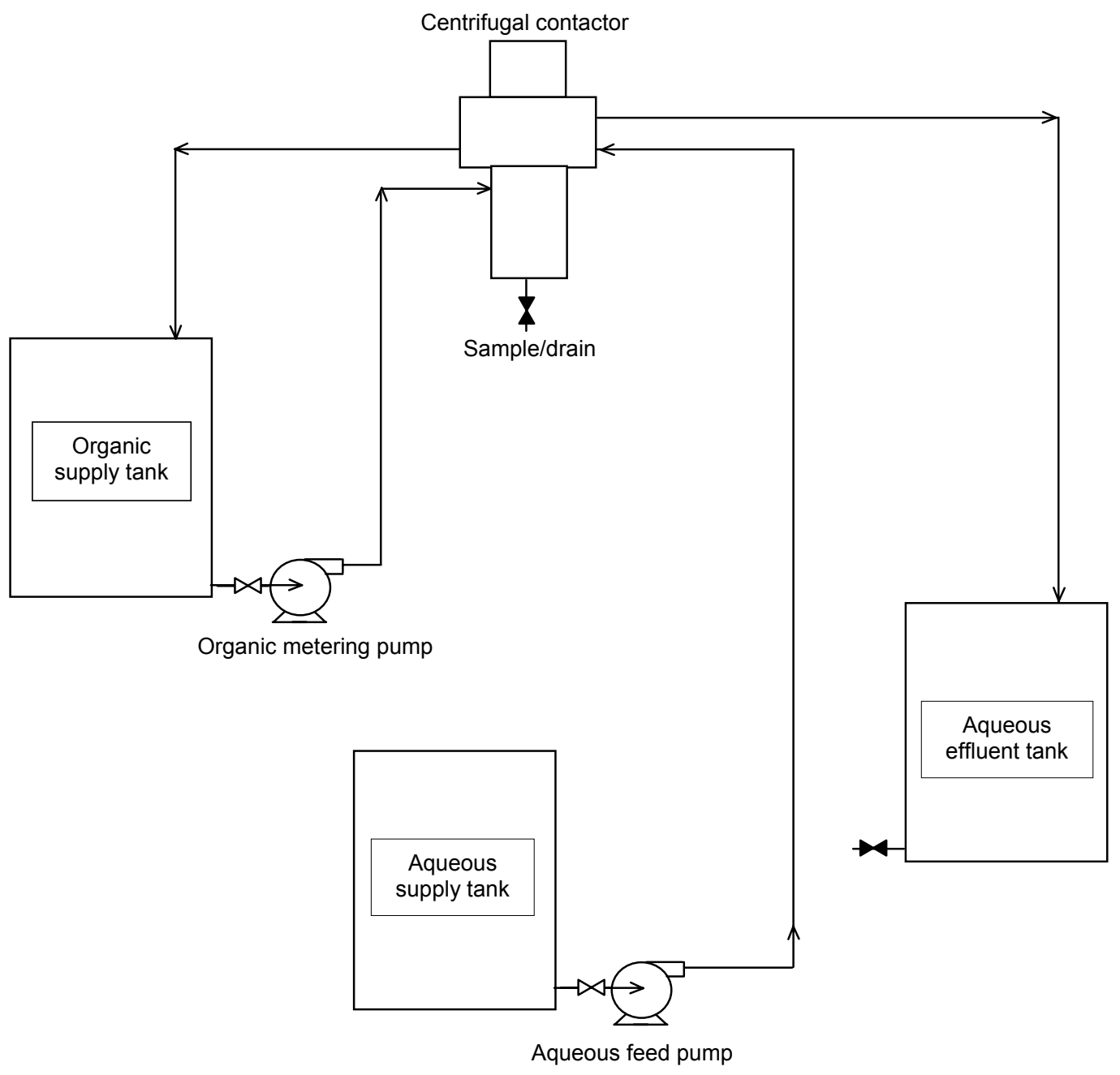

Fig. 1. Schematic of single-contactor configuration for solids-handling evaluation. 
The procedure described was performed both with and without the presence of cesium, metals, and organic constituents in the supernatant. Duplicate experiments with different supernatant compositions were performed to determine if the simplified formulation could be used in contactor tests without changing sludge partitioning performance.

\subsubsection{Contactor Solids Partitioning Procedure}

A total of $12 \mathrm{~L}$ of aqueous feed solution was made for each of three contactor tests by combining supernatant simulant and scrub acid in the 15.2:1.0 ratio specified in the CSSX baseline flow sheet. Sludge was added to the aqueous solution to a concentration of $600 \mathrm{ppm}$. An agitator was placed in the aqueous feed tank, and agitation of the aqueous solution was initiated at least $30 \mathrm{~min}$ prior to introduction of feed to the contactor.

During all solids testing, the flow rates of aqueous and organic feed solutions were maintained at values that had been applied in previous mass transfer testing: $484 \mathrm{~mL} / \mathrm{min}$ aqueous feed and $150 \mathrm{~mL} / \mathrm{min}$ organic feed. All contactor solids testing was performed at a rotor speed of $3600 \mathrm{rpm}$ and with an aqueous weir plate having a diameter of $0.950 \mathrm{in}$.

At the start of each contactor test, only aqueous solution was delivered to the contactor to fill the housing and rotor to their operating inventories. Solvent flow was started when aqueous solution appeared in the discharge from the contactor's aqueous collection trough. Due to the limited supply of solvent available for testing (approximately $2 \mathrm{~L}$ ), the solvent side of the test loop was operated in continuous recycle.

After achieving poor phase separation in the first contactor solids test, a control test without solids was performed to verify contactor phase separation performance. The particular contactor model used in the first solids test had not been used previously with the combination of a partially pumping rotor and a straight-vane housing bottom. The control experiment was performed at the same feed flow rate and rotor speed that were applied in the initial solids test.

Solvent used in contactor tests subsequent to the first one was recovered by allowing the effluents from the first solids test to gravity settle. Prior to its use in the control experiment and the third solids test, solids-free solvent was decanted from the aqueous and organic tanks and then scrubbed, stripped, and washed in the same method as was performed prior to the first solids test. Solvent used in the second solids test (performed after the control experiment) was not treated prior to use.

Because poor phase separation was observed after three start-up attempts, the first solids test was aborted before the aqueous feed inventory was exhausted. The second and third solids tests 
were performed to completion. In both instances, the flow of organic was terminated when the aqueous feed supply was depleted. With the contactor operating, the solution present in the mixing zone was drained from the housing. The solution collected comprised Sample C. Contactor operation was stopped, and the solution from the rotor comprising Sample B was collected from the contactor housing. The contactor was then disassembled; the rotor was removed from the housing and then disassembled and rinsed. The solution collected after the rotor and the aqueous weir plate were rinsed comprised Sample A. The feed and discharge lines were drained into their respective tanks, from which solids were collected. Solids present in the aqueous feed tank, the solvent tank, and the aqueous effluent tank comprised Samples D, E, and $\mathrm{F}$, respectively.

\section{RESULTS}

\subsection{Solids-Phase Partitioning}

After the phases were allowed to separate following the shakeout test with the full simulant formula (cesium, metals, and organic constituents), the greatest fraction of solids was observed to have partitioned to the phase boundary. Considerably smaller fractions were located at the bottom of the graduate and suspended in the bulk aqueous phase. No solids were visible in the bulk organic phase. Similar observations were made when the partitioning test was performed with the reduced supernatant recipe. The bulk aqueous phase was separated from the interfacial sludge layer and the solids-free organic. The two fractions were filtered, and the solids were weighed. Results from this imprecise partitioning determination indicated that approximately two-thirds of the solids present in the system partitioned to the phase boundary regardless of the supernatant formulation used.

Figure 2 is a photograph showing the partitioning of solids to the interface and the aqueous phase.

\subsection{Contactor Solids Partitioning}

In the first contactor solids test, foam was observed in both effluent streams almost immediately after flow of solvent to the contactor was initiated. As operation continued, solids were observed in the organic feed tank and the aqueous effluent tank. Cross-phase contamination of both effluent streams was also observed. Twice during this test, the solution flows were suspended and resumed in attempts to obtain acceptable phase separation. After each resumption of testing, foam and cross-phase contamination reappeared in both effluent streams. Due to the location of the organic supply-line takeoff at the bottom of the organic tank, the organic feed line 
became partially filled with aqueous solution. The test was terminated because acceptable contactor performance was not established. No solids samples were collected.

Manual stripping and washing of the organic tank heel from the first solids test resulted in the formation of a stable interfacial material that extended into the bulk aqueous and organic phases.

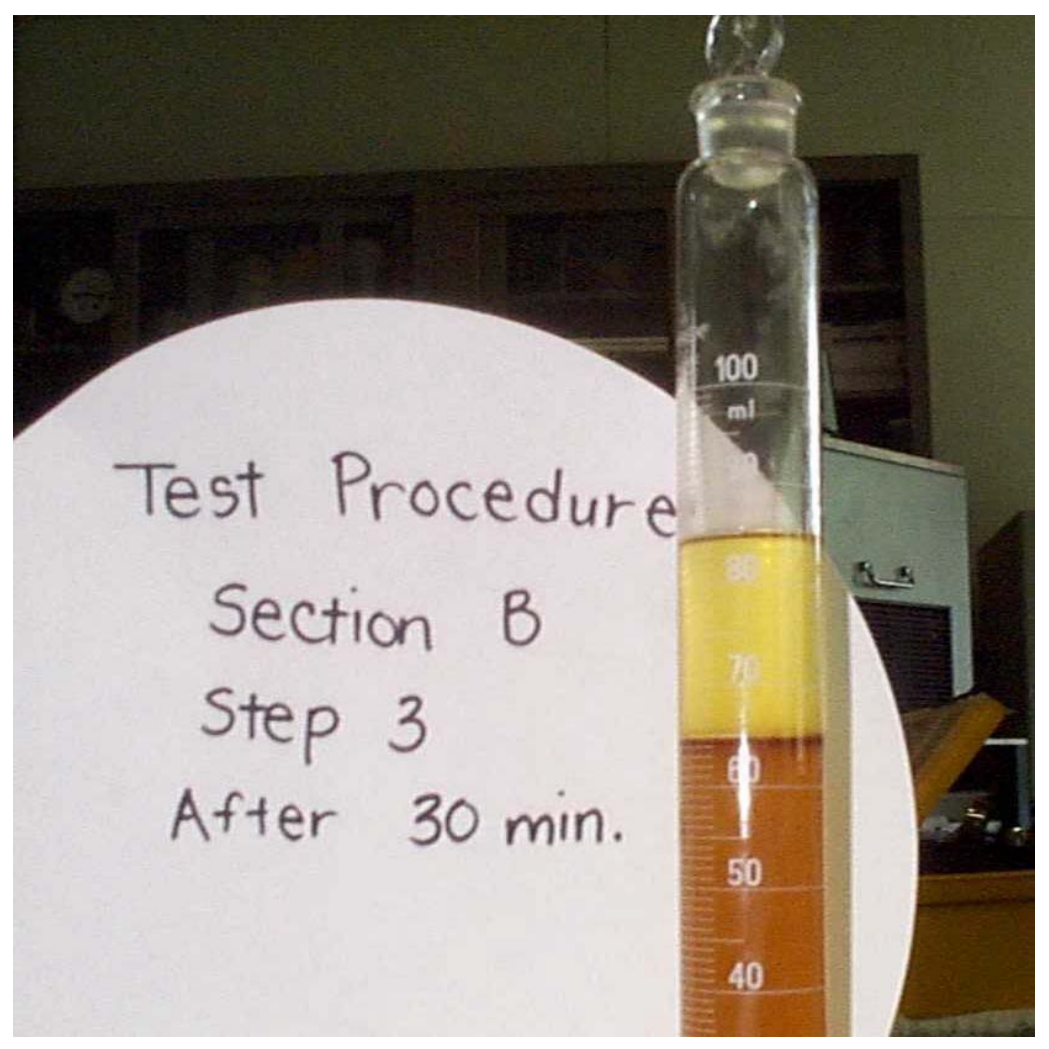

Fig. 2. Solids partitioning in extraction condition shakeout test.

After treating the solvent that was recovered from the first test and making additional supernatant simulant, phase separation testing was performed without solids. Excellent phase separation was obtained when the contactor was operated at the conditions (flow rates, rotor speed, and aqueous weir size) that had been applied during the preceding solids test. No crossphase contamination was observed when the contactor was operated over a range of speeds from 3000 to $4000 \mathrm{rpm}$.

Results from the second solids test were inconsistent with those from the first experiment. Phase separation performance was excellent for the entire test duration. At the completion of 
testing, a small fraction of solids was seen on the bottom of the organic solution tank. A similar quantity of solids was seen on the bottom of the aqueous effluent tank, while a large collection of solids was observed floating on the surface of this tank. Of the samples collected from the contactor, the largest concentration of solids was found in the solution used to rinse the rotor and aqueous weir.

Because of the inconsistency between the results of the first and second contactor solids tests and the difference in solvent preparation, it was decided that a third test would be performed, in which all test parameters and preparation steps would be identical to those of the first test. To expedite the performance of the third test, solids collected from the second test were not weighed and size distribution determinations were not made.

Results of the third solids test were consistent with those of the second test. Phase separation performance was excellent throughout the test. Based on visual observation, solids partitioned to the various system tanks and regions of the contactor as they had in the preceding experiment. Solids collected from this test were washed, filtered, weighed, and sieved; the sieve fractions were then weighed. The rotor was cleaned with dilute $\mathrm{HNO}_{3}$ in an ultrasonic bath to remove any remaining solids. No solids were visible after ultrasonic cleaning, and the rotor weight was equal to its pretest value. The distribution of solids within the contactor and in the system tanks is presented in Table 3.

Table 3. Gross solids distribution results from third contactor solids test Sample identifier and description $\quad$ Sample weight $\quad$ Percent of total solids

\begin{tabular}{lcc}
\hline \multicolumn{1}{c}{ Sample identifier and description } & $\begin{array}{c}\text { Sample weight } \\
(\mathrm{g})\end{array}$ & Percent of total solids \\
\hline A-rinse of contactor and weir & 5.07 & 70.4 \\
B-solids collected from rotor prior to rinsing & 1.22 & 16.9 \\
C-solids collected from contactor mixing & 0.210 & 2.7 \\
$\quad$ zone & & \\
D-remaining solids in aqueous feed tank & 0.314 & 4.3 \\
E-solids in solvent feed tank & $\mathrm{NA}^{a}$ & $\mathrm{NA}^{a}$ \\
F-solids in effluent tank & $\mathrm{NA}^{a}$ & $\mathrm{NA}^{a}$ \\
Rotor weight & 738.4 & Missing $\sim 8.7 \%$ or $0.4 \mathrm{~g}$ \\
\hline
\end{tabular}

${ }^{a}$ Mass of solids collected was extremely small. Solids were dissolved during washing.

Because solids from the solvent and aqueous effluent tanks were lost during washing and because of the small masses of solids collected in Sample C, particle size distribution determinations were made only for Samples A, B, and D. Determinations were made by sorting the solids through a stack of 20-, 45-, 53-, 75-, 90-, 106-, and 125-Fm sieves. Each solids weight 
represents the differences between the final sieve weight and the tare value. Results are provided in Table 4. A size distribution for sludge that was not used in testing is included as a baseline. Because the masses of solids collected in the 53-, 75-, and 90-Fm sieves were very small relative to collections in other sieves, these results have been grouped together, with a single percentage value reported.

Table 4. Particle size distribution of samples from the third contactor solids test ${ }^{a}$

\begin{tabular}{lcccc}
\hline $\begin{array}{c}\text { Particle size range } \\
(\text { Fm) }\end{array}$ & $\begin{array}{c}\text { Sample A } \\
(\%)\end{array}$ & $\begin{array}{c}\text { Sample B } \\
(\%)\end{array}$ & $\begin{array}{c}\text { Sample D } \\
(\%)\end{array}$ & $\begin{array}{c}\text { Baseline sludge } \\
(\%)\end{array}$ \\
\hline$>125$ & 17.2 & 0.0 & 25.0 & 14.6 \\
90 to 125 & 27.6 & 20.0 & 0.0 & 17.4 \\
45 to 90 & 37.9 & 80.0 & 50.0 & 14.4 \\
20 to 45 & 0.0 & 0.0 & 0.0 & 17.9 \\
$<20$ & 17.2 & 0.0 & 25.0 & 35.6 \\
\hline
\end{tabular}

${ }^{a}$ Zero values indicate masses that could not be accurately resolved from tare weights.

\section{DISCUSSION AND CONCLUSIONS}

The observation of significant solids partitioning to the phase boundary following shakeout tests is not favorable for processing of solids in a centrifugal contactor because it is expected that continued accumulation will result in the expansion of the interface into a stable rag layer. This layer will most likely grow inside the rotor until it becomes located under either the light-phase weir or the heavy-phase underflow. At either position the rag layer, which will consist of both solution phases and suspended solids, will begin to exit the contactor in one of the effluent streams, resulting in cross-phase contamination.

The results of the first contactor solids test are inconsistent with two succeeding tests. Poor phase separation observed during the first test may have been due to incomplete removal of solutions that were used to rinse the contactor prior to this test. This supposition is supported by the formation of a stable interfacial material during manual stripping and washing of the solution heel from the solvent tank after the first contactor solids test. In addition, emulsion formation has been reported in washing operations involving the CSSX solvent. ${ }^{4}$ The inability to achieve good phase separation after several restart attempts was undoubtedly exacerbated by a shift in the organic-to-aqueous flow ratio, which resulted from accumulation of aqueous solution in the organic feed tank.

Visual observations from the second and third solids tests and quantitative results from the third test indicate that most of the solids delivered to the contactor were retained within the 
contactor rotor. This result is consistent with previous contactor experience in non-CSSX applications. Sludge that accumulated in the contactor contained a small fraction of solids (less than $20 \mathrm{Fm}$ ) when compared with the baseline sludge. This result tends to indicate that solids are not reduced in size as they pass through the contactor. The lack of any significant variation in solids size retention within the rotor as a function of particle size indicates no minimum size removal requirement for the CSSX process.

Based on the large fraction of solids that was retained in the contactor rotor during testing, it is anticipated that extended operation of the contactor with a solids-containing feed solution would eventually result in restricted flow and loss of phase separation performance. Based on the results of the test program, CSSX processing without prior clarification of the tank waste feed stream is not recommended.

\section{REFERENCES}

1. Personal communication, Joe Carter, Savannah River Site, to Leon N. Klatt, Oak Ridge National Laboratory, February 16, 2001.

2. R. A. Peterson, Preparation of Simulated Waste Solutions for Solvent Extraction Testing, WSRC-RP-2000-00361, Westinghouse Savannah River Company, Aiken, S.C., May 2000.

3. Joseph F. Birdwell, Jr., and Kimberly K. Anderson, Evaluation of 5-cm Centrifugal Contactor Hydraulic and Mass Transfer Performance for Caustic-Side Solvent Extraction of Cesium, ORNL/TM-2001/137, Oak Ridge National Laboratory, Oak Ridge, Tenn., August 2001.

4. S. G. Campbell et al., Demonstration of Caustic-Side Solvent Extraction with Savannah River Site High Level Waste, WSRC-TR-2001-00223, Rev. 0, Westinghouse Savannah River Company, Aiken, S.C., April 2001. 